\title{
Advancing health policy development through cross-cultural teams: examples from two global maternal and child health policies
}

\author{
Kathryn Mishkin ${ }^{1}$ - Inon Schenker ${ }^{1}$
}

Accepted: 16 November 2021 / Published online: 23 November 2021

(c) The Author(s), under exclusive licence to Springer Nature Limited 2021

\section{Dear Editor,}

Public health policy is an essential and powerful tool to improve the health and wellbeing of populations. Policy can mobilize resources, increase public awareness, support professional engagement, and direct research and actions. Failures to limit the harm of the COVID-19 pandemic around the world has presented starkly the need to revisit policy development in public health [1]. The literature presents discussion and differences of opinion about appropriate pandemic responses of practitioners, academicians, public health officers in the field, and health decision makers at national, state, and community levels [2,3] Analysis of the process to drive action and change of the American Public Health Association, a well-established organization, offers lessons for similar efforts in many others.

The American Public Health Association (APHA) is committed to improving the health of all people and occupies a unique position to influence federal policy in the United States and influences actions by civil society and the private sector. Adopted APHA policy statements guide APHA staff, members, affiliates, and policy makers around the world on health topics. Public health leaders have used APHA policies to impact public health action and outcomes. For example, commentary on the 2015 Dietary Guidelines Advisory Committee's scientific report submitted to the U.S. Department of Agriculture and U.S. Department of Health and Human Services used several APHA policy statements [4]. More recently, an amicus brief to the U.S. Supreme Court included language from APHA policy statements to advocate for improved access to abortion care in Louisiana [5].

Kathryn Mishkin

kemishkin@hotmail.com

Inon Schenker

gmchn.p@gmail.com

1 Global Maternal and Child Health Network, American Public Health Association, Washington, DC, USA 
Table 1 Sample steps and timeline in policy development process used by the American Public Health Association

\begin{tabular}{|c|c|}
\hline Early February & Proposed policy statements due via email to APHA Leadership \\
\hline Late February & $\begin{array}{l}\text { Proposed policy statements posted on APHA's website for APHA } \\
\text { member review }\end{array}$ \\
\hline Late March & APHA member comments on proposed statements due via email \\
\hline Late April & $\begin{array}{l}\text { APHA's Leadership meet to review proposed policy statements and } \\
\text { member comments }\end{array}$ \\
\hline End of May & $\begin{array}{l}\text { Deadline for APHA leadership email authors of proposed policy state- } \\
\text { ments with comments and assessments }\end{array}$ \\
\hline Mid-August & $\begin{array}{l}\text { Revised proposed policy statements based on APHA Leadership com- } \\
\text { ments due }\end{array}$ \\
\hline Early September & $\begin{array}{l}\text { APHA Leadership holds a conference call to discuss status of proposals } \\
\text { that were revised }\end{array}$ \\
\hline Early October & $\begin{array}{l}\text { Revised proposed policy statements and comments from APHA Leader- } \\
\text { ship posted on APHA's website }\end{array}$ \\
\hline Late October-annual meeting & $\begin{array}{l}\text { Public hearings for proposed policy statements held at APHA's Annual } \\
\text { Meeting }\end{array}$ \\
\hline Late October-annual meeting & $\begin{array}{l}\text { APHA Leadership develops final recommendations for proposed policy } \\
\text { statements to present to Governing Council }\end{array}$ \\
\hline Late October-annual meeting & $\begin{array}{l}\text { The Governing Council considers the recommendations on proposed } \\
\text { policy statements and votes on proposed to adopt or not adopt policy } \\
\text { statements }\end{array}$ \\
\hline
\end{tabular}

The Association's bylaws set out a process for developing APHA policy statements (See Table 1). Every member may develop, present, advocate, and lobby for endorsement of APHA policy statement proposals in any public health domain. The bylaws include timelines for submitting proposed statements, responding to requests for edits, and participating in the Annual Meeting public health hearings to make final decisions to accept the proposed policies. For each review period, two groups of APHA leaders dedicated to supporting the development of proposed policies, invite all leaders from membership groups to review and comment on proposals to ensure the quality and scientific merit of the statements. APHA leadership then rates the strength of proposals and only authors of policy statement proposals that have been accepted to participate may present their proposed statements at the public hearings. The organization's Governing Council, an elected group of APHA leaders, votes to officially adopt policy statements at the Annual Meeting.

Since APHA policy statements are useful tools for advocating for public policy and influencing practice at national and international level, we present methods and experiences that may be useful to advance policy development in public health as described through development of two specific APHA policies by international and cross-sectoral teams. The lessons learned are important for policies targeting intersectional and pressing issues.

The two examples of policies we present were developed through efforts by the Global Maternal and Child Health Network (GMCHN), a group of APHA members that aims to provide opportunity for APHA members to collaborate on global 
maternal and child health $(\mathrm{MCH})$ issues. Investment in and advocacy for global $\mathrm{MCH}$ has never been more important [6]. The World Health Organization estimates that over 800 women die from preventable causes in pregnancy through one year postpartum and that millions of children under the age of five years die each year, half of whom within the first month of life [7]. The Lancet has called for renewed global efforts to attain milestones in the fields of $\mathrm{MCH}$, gender, and women's empowerment [8].

From 2016 to 2019, members of the GMCHN authored two policies adopted by the APHA Governing Council [6]:

- In 2018: statement 20,181: Promoting Leadership to Scale Up of Oral Rehydration Salts with Zinc Uptake and Reduce Diarrhea Mortality Globally in Children Under 5 Years, and

- In 2019: 20,192: A Global Call to Action to Improve Health Through Investment in Maternal Mental Health, which was adopted in 2019.

These policies are important for tangible impact for practice on the world stage. For example, the policy about oral rehydration salts (ORS) and children under age five was used to gain support for a World Health Organization decision to include oral rehydration salts and zinc (ORS/Z), co-packaged, on its Model List of Essential Medicines 7th List 2019 for Children [9]. This effort also gained traction in professional publications $[10,11]$ and became the focus of a global webinar hosted by APHA, which facilitated discussion about policy to reduce childhood deaths due to diarrhea.

While APHA allows for policies to be developed by individuals as well as teams, developing policies in multi-sectoral teams offers notable benefits. The process that GMCHN followed for working with diverse author teams is as follows:

- The larger group of GMCHN members decide key priority issues to address through policy. In the two examples, members identified candidate issues based on perceived gaps, news reports, and individual experience.

- The GMCHN put out a call for voluntary participation of authors with details on deadlines for application, the desired number of authors, and author selection criteria. GMCHN prioritized diversity in selecting the authorship team to ensure representation from different cultures, genders, geographic locations, and expertise, among other considerations.

- A primary (lead) author for each policy led the team by providing strategic and technical leadership. For writing statements, the team relied on volunteer subgroups: a Science team (to review the literature), a Drafting team (to convert science into narrative), a Reference team (to verify accuracy of citations), and a Language Editor. Team members also requested support for the statements in the form of written endorsements from APHA member groups.

- The primary author of each writing team aimed to conduct meetings in a democratic manner. This required accommodations as teams included a diversity of members from different countries: members reflected a diversity of backgrounds, views of the issues, and worked in different time zones. Teams used tele-confer- 
encing for routine meetings to ensure inputs from participants in all settings, and drafted policy statements using electronic shared documents maintained by the lead author.

- The communication structure of these team meetings and access to shared resources facilitated communication by enabling genuine discussion and sharing differences of opinions that led to stronger policy documents.

The process to develop each of these GMCHN policy statements relied on team members' commitment to and expertise on global MCH. The author teams consisted of researchers, practitioners, and students who were from multiple APHA membership groups. Research shows that interacting with diverse teams can result in less cross-sectoral collaborative thinking [12]. We suggest that the quality of these two policy statements was supported by engaging the diversity of experiences and expertise of their multidisciplinary team members. For example, the evidence and recommendations included in the policies focused on opportunities for improvements for population health including reduced mortality and morbidity for moms and babies, and on reducing economic burden through novel changes to the delivery of health care.

Lead authors for both groups aimed for cohesive team work using transformational leadership to engage expertise of all group members, a "process by which a leader fosters group or organizational performance beyond expectation by virtue of the strong emotional attachment with his or her followers combined with the cohesive commitment to a higher moral cause" [13]. Some observers describe this as a critical tactic to connect a group of seemingly disparate individuals [14]. The leader may take the form of a mentor, facilitator, or stimulator who encourages commitment of individuals to the team and generates team cohesion [14]. Research shows that work performance and commitment both correlate with a transformational leadership approach [15].

Peer support and division of labor in teams added great value-as the African proverb suggests, "If you want to go fast, go alone. If you want to go far, go together [16]". The literature shows that teams mediate burnout from overwork and emotional exhaustion [17]. Even though teams naturally work slower than individuals, teams offer longer sustained commitment to the goals. Using author teams, GMCHN distributed the tasks of writing, editing, and requesting endorsement across multiple authors.

Further, the teams' clearly defined roles and responsibilities helped the process from the beginning of the writing through completion. Division of labor ensured accomplishment of all tasks, and equitable contributions by authors according to their strengths.

Developing policy in cross-cultural and international teams is a rewarding public health collective effort that can produce effective and comprehensive multidisciplinary policies with potential impact on important public health issues. The GMCHN's successful development of two adopted policies within a three-year period present examples of the effects of multi-sectoral collaboration. We encourage incorporation of diverse perspectives through engaged teams to develop meaningful policy. 
Further, the transformational leadership style employed by the GMCHN for policy statement development is a critically important strategy to engage multiple actors on policy development across organizational settings. We advocate for organizations to consider and invest in transformational leadership to address public health issues through collaborative teams.

\section{Declarations}

Conflict of interest On behalf of all authors, the corresponding author states that there is no conflict of interest.

\section{References}

1. Friedman A. Coronavirus and the crisis of trust. 2021. https://www.thehastingscenter.org/coron avirus-and-the-crisis-of-trust/

2. Paquet M, Schertzer R. COVID-19 as a complex intergovernmental problem. Can J Polit Sci Can Sci Polit. 2020;53(2):343-7.

3. DeRoo SS, Pudalov NJ, Fu LY. Planning for a COVID-19 vaccination program. JAMA. 2020;323(24):2458-9.

4. APHA. Importance and use of APHA policy statements. https://www.apha.org/-/media/files/pdf/ policy/importance_use_policy_statements.ashx?la=en\&hash=181F9AD4671D8D660EAA7E100 C940BD7CDE6D8FA

5. Brief of amici curiae American College of Obstetricians and Gynecologists, American Medical Association, American Academy of Family Physicians, American Academy of Nursing, American Academy of Pediatrics, et al. In support of June medical services, L.L.C. 2019. https://www.apha. org/-/media/files/pdf/advocacy/briefs/191125_june_v_gee_amicusbrief.ashx

6. APHA. American Public Health Association. 2020. https://www.apha.org/

7. World Health Organization. Maternal, newborn, child and adolescent health. 2020. https://www. who.int/maternal_child_adolescent/en/

8. Lancet. 2020: a critical year for women, gender equity, and health. Lancet. 2020;395(1).

9. World Health Organization. World Health Organization Model List of Essential Medicines for Children, 7th List 2019. 2019. https://apps.who.int/iris/bitstream/handle/10665/325772/WHO-MVPEMP-IAU-2019.07-eng.pdf?ua=1 (p.30)

10. Trehan MD, MPH, DTM\&H I, Grabowsky MD, MPH M, Schenker PhD, MPH I. Oral rehydration therapy and zinc: looking back and looking ahead. J Trop Pediatr. 2019 Jul 24;65(5):417-20. https:// doi.org/10.1093/tropej/fmz052

11. Schenker I, Brofksy E. We have the power to save children's lives. We must act. 2019. https://www. globalhealthnow.org/2019-07/we-have-power-save-childrens-lives-we-must-act

12. Gaertner SL, Mann J, Murrell A, Dovidio JF. Reducing intergroup bias: the benefits of recategorization. J Pers Soc Psychol. 1989;57(2):239.

13. Diaz-Saenz HR. Transformational leadership. SAGE Handb Leadersh. 2011;5(1):299-310.

14. Disis ML, Slattery JT. The road we must take: multidisciplinary team science. Sci Transl Med. 2010;2(22):22-229.

15. Limsila K, Ogunlana SO. Performance and leadership outcome correlates of leadership styles and subordinate commitment. Eng Constr Archit Manag. 2008

16. Kallestrup P, Schriver M, Lindbaek M, Hjortdahl P. "If you want to go fast, go alone. If you want to go far, go together": a call for a Nordic engagement in the development of family medicine in Africa. Scand J Prim Health Care. 2013/09/20. 2013;31(4):183-4

17. Fernet $\mathrm{C}$, Gagné $\mathrm{M}$, Austin $\mathrm{S}$. When does quality of relationships with coworkers predict burnout over time? The moderating role of work motivation. J Organ Behav. 2010;31(8):1163-80. 
Publisher's Note Springer Nature remains neutral with regard to jurisdictional claims in published maps and institutional affiliations.

Kathryn Mishkin, DrPH, MPH, MA is Chair of the Global Maternal and Child Health Network of the American Public Health Association. She serves as Senior Director of Science, Data, Evaluation, and Innovation at the March of Dimes in Arlington, VA, USA.

Inon Schenker, PhD MPH serves on the Steering Committee of the Global Maternal and Child Health Network of the American Public Health Association. He serves as Senior Global Public Health Specialist with IMPACT Consulting in Jerusalem, Israel. He is a Co-Chair of the Diarrhea Innovation Group (DIG), UNICEF-CHAI in New York, USA. 